\title{
STRATEGI PEMBELAJARAN PENDIDIKAN AGAMA KRISTEN DI PUSAT PENGEMBANGAN ANAK IO-0497 BENYAMIN OEBUFU
}

\author{
Yusuf Tanaem, Imelda Djira \\ Institut Agama Kristen Negeri Kupang \\ yusuftanaem86@gmail.com
}

\begin{abstract}
This study aims to identify strengths, weaknesses, opportunities, and threats and then determine the learning strategy of Christian Religious Education (CRE) in PPA 10-0497 Benyamin Oebufu. This study used a qualitative method with a descriptive approach and data analysis using a SWOT analysis. The steps in this research are observation and literature study, problem identification and formulation, data collection, data processing, discussion, and conclusion drawing. The subjects in this study consisted of two management bodies and four mentors. The results showed that PPA 10-0497 Benyamin Oebufu had 11 strengths, eight weaknesses, six opportunities, and six threats. The results show that the position of the PAK learning strategy in PPA $1 O-0497$ Benyamin Oebufu is in the Quadrant I area, meaning that growth strategies are possible because strengths are more significant than weaknesses and opportunities are more significant than threats. The CRE learning strategy at PPA IO-0497 Benyamin Oebufu is the integration of learning with God's Word, applying creative and interesting technologybased Bible learning, building a spiritual community to grow together, conducting competency-building training for mentors, and conducting pastoral counseling for children and parents.
\end{abstract}

Keywords: Christian Religious Education Strategy, Benyamin Oebufu Child Development Center, SWOT Analysis, Matrix Space Analysis

\begin{abstract}
Abstrak. Penelitian ini bertujuan mengidentifikasi kekuatan, kelemahan, peluang dan ancaman kemudian menentukan strategi pembelajaran Pendidikan Agama Kristen di PPA IO-0497 Benyamin Oebufu. Penelitian ini menggunakan metode kualitatif dengan pendekatan deskriptif serta analisis data menggunakan analisis SWOT. Langkah-langkah dalam penelitian ini adalah observasi dan studi literatur, identifikasi dan perumusan masalah, pengumpulan data, pengolahan data, pembahasan serta penarikan kesimpulan. Subyek dalam penelitian ini sebanyak enam orang yang terdiri dari dua orang badan pengurus dan empat orang mentor. Hasil penelitian menunjukkan bahwa PPA 1O-0497 Benyamin Oebufu memiliki sebelas kekuatan, delapan kelemahan, enam peluang dan enam ancaman. Hasil matrix space analysis menunjukkan posisi strategi pembelajaran PAK di PPA IO - 0497 Benyamin Oebufu berada dalam wilayah Kuadran I, artinya strategi bertumbuh sangat dimungkinkan karena kekuatan lebih besar dari kelemahan dan peluang lebih besar dari ancaman. Strategi pembelajaran PAK di PPA IO-0497 Benyamin Oebufu adalah integrasi pembelajaran dengan Firman Tuhan, menerapkan pembelajaran Alkitab berbasis teknologi yang kreatif dan menarik, membangun komunitas rohani tumbuh bersama, mengadakan diklat peningkatan kompetensi bagi mentor serta melakukan pastoral konseling bagi anak dan orang tua.
\end{abstract}

Kata kunci: Strategi Pendidikan Agama Kristen, Pusat Pengembangan Anak Benyamin Oebufu, Anaisisis SWOT. Matrix Space Analysis 
Di era globalisasi sekarang ini, lembaga pendidikan harus memiliki kemampuan manajemen yang baik. Lembaga pendidikan dituntut memiliki kompetensi manajerial, yakni kemampuan membangun pola kerja yang sistematis, logis, realistis dan strategis. (Khori, 2016).

Tugas bidang pendidikan tidak hanya pada pencapaian kuantitas pendidikan, tetapi juga pada kualitas pendidikan yang diberikan kepada para calon penerus bangsa. (Alawiyah, 2017). Hal ini berarti bahwa bagi lembaga pendidikan dibutuhkan manajemen strategi untuk bisa bersaing serta meningkatkan kualitas layanannya kepada masyarakat.

Manajemen strategi merupakan proses pengambilan keputusan yang bersifat mendasar dan menyeluruh agar diimplementasi seluruh jajaran dalam organisasi untuk mencapai tujuannya. (Rindaningsih, 2012). Manajeman strategi dilaksanakan untuk mengetahui secara tepat kekuatan, kelemahan peluang dan ancaman kemudian merumuskan suatu rencana jangka panjang. (Baharuddin, 2019).

Perumusan rencana jangka panjang tersebut dilakukan dengan cara menganalisis lingkungan internal dan lingkungan eksternal biasanya disebut sebagai analisis SWOT. (Primadona \& Rafiqi, 2019). Analisis SWOT mengembangkan kekuatan dan kelemahan pada lingkungan internal dengan peluang dan ancaman pada lingkungan eksternal. (Arifianto, 2017). Tujuan dilaksanakan analisis SWOT adalah untuk mengidentifikasi faktor strategis, elemen internal dan eksternal untuk 
memutuskan strategi di masa yang akan datang. (Anwar dan Utami, 2012)

Pembelajaran Pendidikan Agama Kristen (PAK) yang dilaksanakan oleh lembaga pendidikan juga perlu dikelola agar tujuannya pun tercapai dengan baik. PAK bertujuan untuk membimbing, memperlengkapi dan mendewasakan iman para murid Kristus. (Oci, 2018). Selain itu, PAK juga bertujuan mengajarkan Firman Tuhan, membawa perjumpamaan dengan Kristus, mengajarkan hidup bersama, dan membawa murid untuk memiliki spiritualitas seperti Kristus. (Yulianingsih \& Gaol, 2019).

Gereja memiiki tugas untuk mendidik dan membelajarkan pendidikan Kristen bagi warga gereja agar memiliki kedewasaan secara holistik, khususnya kedewasaan spiritual. (Hasugian, 2019). Pelaksanaan PAK bukan tugas gereja semata, tetapi keluarga juga bertanggung jawab dalam pelaksanaannya. (Gulo, 2017). Mengingat pentingnya hal ini, maka berbagai yayasan maupun organisasi lokal menyelenggarakan pendidikan dan pengajaran untuk membelajarkan PAK. Salah satunya adalah Pusat Pengembangan Anak (PPA).

Penelitian yang dilakukan di SMK Maarif Kabupaten Kebumen tentang analisa SWOT manajemen pendidikan (Chamidi et al., 2019) untuk mengetahui penyelenggaraan manajemen pendidikan di sekolah tersebut. Penelitian ini bersifat kualitatif dengan analisis SWOT. Penelitian ini hanya mengevaluasi strategi yang sudah dilaksanakan namun tidak 
merumuskan strategi baru. Hasil penelitian tersebut menemukan bahwa manajemen pendidikan di sekolah ini sudah berjalan dengan baik.

Penelitian lain dilakukan di SMPN 1 Bawen kabupaten Semarang tentang strategi peningkatan mutu sekolah berdasarkan analisis SWOT (Sujoko, 2017) bertujuan mendeskripsikan faktor yang menjadi kekuatan, kelemahan, peluang dan ancaman serta menyusun strategi untuk meningkatkan mutu sekolah tersebut. Penelitian ini menggunakan metode pengembangan dengan analisis SWOT. Hasil penelitian tersebut berupa strategi baru peningkatan mutu sekolah dilaksanakan dari aspek input, proses dan output. Aspek input menciptakan strategi dengan mengembangkan potensi sekolah. Aspek proses menciptakan strategi dengan mengoptimalkan potensi sekolah berdasarkan peluang yang ada. Aspek ouput menciptakan strategi berdasarkan peluang yang ada. Penelitian ini hanya merumuskan strategi dengan memaksimalkan kekuatan dan menangkap peluang namun tidak menciptakan strategi untuk mengatasi kelemahan dan meminimalisir ancaman.

Selanjutnya penelitian yang dilakukan di Sekolah Swasta Salatiga tentang perencanaan strategi bersaing sekolah dalam meningkatkan mutu pendidikan (Kamayuda \& Krismanda, 2016) untuk mengembangkan perencanaan strategi kompetitif dalam meningkatkan jumlah siswa baru. Penelitian ini menggunakan metode $R$ \& $D$ dengan analisis SWOT. Penelitian ini juga melakukan FGD untuk untuk menganalisis masalah dan menentukan faktor internal berupa kekuatan dan kelemahan serta faktor 
eksternal berupa peluang dan ancaman. Hasil penelitian menunjukkan bahwa sekolah menggunakan kekuatan lingkungan internal untuk menangkap peluang dari lingkungan eksternal.

Ketiga penelitian di atas memang dilaksanakan di lingkup pendidikan formal. Belum ada penelitian sejenis di lingkup pendidikan informal maupun PPA. Oleh karena itu artikel ini menggunakan penelitian di pendidikan formal sebagai acuan untuk penelitian di pendidikan informal.

Pusat Pengembangan Anak (PPA) IO-0497 Benyamin Oebufu sebagai bagian dari Yayasan Compassion Indonesia (YCl) menyelenggarakan pendidikan bagi anak-anak dengan berfokus pada pada perkembangan dan kebutuhan anak yang dilayani. $\mathrm{YCl}$ bermitra dengan gereja lokal untuk menyelenggarakan pendidikan non formal (setelah jam pelajaran sekolah) untuk memberikan pembinaan bagi anakanak.

PPA fokus pada pengkembangan keterampilan, kepribadian dan spiritual anak dan bertujuan memuridkan anak. PPA membutuhkan manajemen strategi agar visi PPA dapat terwujud. Analisis SWOT perlu dilakukan agar bisa mengidentifikasi kekuatan, kelemahan, peluang dan ancaman dari PPA IO-0497 Benyamin Oebufu kemudian merumuskan strategi baru demi pencapaian visi, yaitu menghasilkan orang Kristen yang dewasa dan bertanggungjawab. 
Penelitian ini berbeda dari penelitian-penelitian sebelumnya. Penelitian ini menggunakan metode kualitatif dengan pendekatan deskriptif serta analisis SWOT. Wawancara dilakukan untuk mengidentifikasi kekuatan, kelemahan, peluang dan ancaman. Hasil wawancara dibuat angket untuk pembobotan dan selanjutnya dianalisis dengan analisis SWOT untuk merumuskan strategi baru.

Penelitian ini bertujuan mengidentifikasi kekuatan, kelemahan, peluang dan ancaman dari PPA 1O-0497 Benyamin Oebufu. Kemudian dilakukan analisis SWOT untuk menentukan strategi pembelajaran PAK di PPA IO-0497 Benyamin Oebufu.

\section{METODE}

Penelitian ini menggunakan metode kualitatif dengan pendekatan deskriptif, yaitu menggambarkan secara sistematis secara faktual dan akurat mengenai fakta, sifat dan hubungan yang diselidiki (Arifianto, 2017) serta analisis data menggunakan analisis SWOT (Shamadiyah, 2017).

Teknik pengumpulan data yang digunakan yaitu wawancara dan penyebaran angket. Wawancara dilakukan kepada 4 orang mentor dan 2 orang staf untuk mengidentifikasi kekuatan, kelemahan, peluang dan ancaman. Setelah data diolah, dilakukan penyebaran angket kepada 6 orang subyek untuk skoring matriks analisis.

Pengolahan data dilakukan 2 tahap, yaitu mengolah hasil wawancara menjadi kekuatan, kelemahan, peluang dan ancaman. Setelah 
melakukan penyebaran angket, dilakukan pengolahan data pada matriks IFAS, EFAS, matrix space analisys dan maktriks SWOT.

\section{HASIL}

Berdasarkan hasil wawancara, diperoleh 4 poin pokok dalam SWOT, yaitu:

\section{Kekuatan}

1) Setiap Materi Pembelajaran berdasarkan ayat Alkitab.

2) Bagian pembelajaran yang dikembangkan yaitu kerohanian, kognitif, fisik dan sosial emosional.

3) Pengajar merupakan guru Pelayanan Anak dan Remaja (PAR) lebih dari 3 tahun sehingga sudah memiliki dasar mengajar.

4) Mengutamakan penerapan Firman Tuhan dari setiap pembelajaran dengan menghafal Firman.

5) Terdapat perubahan yang signifikan dalam diri anak.

6) Pengajar sudah mengenal latar belakang anak.

7) Mentor yang kreatif.

8) Fasilitas yang memadai.

9) Lingkungan yang bersahabat.

10) Hubungan kekeluargaan yang tinggi.

11) Dukungan dari orang tua anak.

\section{Kelemahan}

1) Belum optimal kreativitas dalam pembelajaran.

2) Anak tidak hadir karena malas. 
3) Masalah anak dalam keluarga yang membuat anak tidak ke PPA.

4) Beban belajar anak di Sekolah dan PPA yang semakin banyak.

5) Tidak semua pengajar berasal dari lulusan guru agama Kristen.

6) Pembelajaran masih bersifat dasar, belum mengembangkan potensi anak.

7) Belum membelajarkan materi yang sesuai perkembangan anak.

8) Kurang konsistensi dalam kedisiplinan dan keteladanan.

\section{Peluang}

1) Anak-anak menjadi Ester dan Daniel di masa depan.

2) Anak-anak aktif dalam pelayanan gereja.

3) Pengajar menggunakan perkembangan teknologi untuk pembelajaran yang kreatif.

4) Pengajar menggunakan internet untuk proses pembelajaran.

5) Mengajar sesuai realita di lapangan sehingga tidak membingungkan anak.

6) Menjadi contoh bagi orang lain.

\section{Ancaman}

1) Anak lebih fokus dengan gadget saat pembelajaran.

2) Kurang dukungan, pengawasan dan keteladanan orang tua terhadap anak.

3) Ketidakpedulian anak terhadap pembelajaran Agama Kristen.

4) Perkembangan internet yang gampang diakses anak.

5) Pengurusan surat / administrasi anak yang tidak lancar. 
6) Pengaruh dunia luar bagi karakter anak.

Hasil wawancara di atas berupa kekuatan, kelemahan, peluang dan ancaman, selanjutnya disusun menjadi angket/quisioner dan disebarkan untuk pemberian bobot. Pembobotan ini bertujuan untuk mendapatkan isu strategis di PPA IO-0497 Benyamin Oebufu. Hasil pembobotan tersebut sebagai berikut:

Internal Factor Analysis Strategy (IFAS)

Tabel 1. IFAS

Faktor Strategis Internal

Bobot Rating Skor

\section{KEKUATAN}

S1 Setiap Materi Pembelajaran berdasarkan ayat Alkitab

$0,06 \quad 5,0 \quad 0,294$

S2 Bagian pembelajaran yang

dikembangkan yaitu kerohanian, kognitif, $\quad 0,06 \quad 5,0 \quad 0,294$ fisik dan sosial emosional

S3 Pengajar merupakan guru PAR lebih dari 3 tahun sehingga sudah memiliki dasar mengajar

$0,05 \quad 4,2 \quad 0,198$

S4 Mengutamakan penerapan Firman Tuhan dari setiap pembelajaran dengan menghafal Firman

$0,06 \quad 5,0 \quad 0,294$

S5 Terdapat perubahan yang signifikan dalam diri anak

$0,05 \quad 4,2 \quad 0,198$

S6 Pengajar sudah mengenal latar belakang anak

$0,06 \quad 4,6 \quad 0,271$

S7 Mentor yang kreatif

$0,05 \quad 4,2 \quad 0,198$

S8 Fasilitas yang memadai

$0,05 \quad 4,0 \quad 0,188$

S9 Lingkungan yang bersahabat

$0,05 \quad 4,4 \quad 0,207$


S10 Hubungan kekeluargaan yang tinggi

0,06

4,8

0,282

S11 Dukungan dari orang tua anak

0,05

3,6

0,169

Total

2,593

\section{KELEMAHAN}

W1 Belum optimal kreativitas dalam pembelajaran

$0,05 \quad 2,6 \quad 0,122$

$0,04 \quad 2,0 \quad 0,071$

W2 Anak tidak hadir karena malas

$0,06 \quad 2,8 \quad 0,165$

W3 Masalah anak dalam keluarga yang membuat anak tidak ke PPA

$0,06 \quad 3,2 \quad 0,188$

PPA yang semakin banyak

W5 Tidak semua pengajar berasal dari lulusan guru agama Kristen

$0,06 \quad 2,8 \quad 0,165$

W6 Pembelajaran masih bersifat dasar, belum mengembangkan potensi anak

$0,06 \quad 3,2 \quad 0,188$

W7 Belum membelajarkan materi yang sesuai dengan perkembangan anak

$0,06 \quad 2,8 \quad 0,165$

W8 Kurang konsistensi dalam kedisiplinan dan keteladanan

$0,05 \quad 2,8 \quad 0,132$

Total

1,195

External Factor Analysis Strategy (EFAS)

Tabel 2. EFAS

Faktor Strategis Eksternal

Bobot Rating Skor

\section{PELUANG}

O1 Anak-anak menjadi Ester dan Daniel di masa depan

$0,09 \quad 5,0 \quad 0,446$ 
O2 Anak-anak aktif dalam pelayanan gereja

$\begin{array}{lll}0,09 & 4,8 & 0,429 \\ 0,09 & 5,0 & 0,446\end{array}$

O4 Pengajar menggunakan internet untuk proses pembelajaran

$0,09 \quad 4,6 \quad 0,411$

O5 Mengajar sesuai realita di lapangan $\quad 0,07 \quad 4,4 \quad 0,314$

$\begin{array}{llll}\text { O6 Menjadi contoh bagi orang lain } \quad 0,07 & 3,8 & 0,271\end{array}$ $\begin{array}{ll}\text { Total } & 2,318\end{array}$

\section{ANCAMAN}

T1 Anak lebih fokus dengan gadget saat pembelajaran

$\begin{array}{lll}0,09 & 2,1 & 0,188 \\ 0,09 & 1,9 & 0,170\end{array}$

T2 Kurang dukungan, pengawasan dan keteladanan orang tua terhadap anak

$0,07 \quad 1,8 \quad 0,129$

T4 Perkembangan internet yang gampang diakses anak

$0,09 \quad 2,0 \quad 0,179$

T5 Pengurusan surat / administrasi anak yang tidak lancar

$0,07 \quad 3,0 \quad 0,214$

T6 Pengaruh dunia luar terhadap karakter anak

$0,09 \quad 1,6 \quad 0,143$

Total

Hasil pengolahan data pada matriks evaluasi internal dan matriks evaluasi eksternal digunakan untuk melakukan analisis kuadran untuk menentukan koordinat pada Matrix Space Analysis. Hasilnya adalah:

Nilai Matriks evaluasi internal $=$ Total Kekuatan - Total Kelemahan

$$
\begin{aligned}
& =2,593-1,195 \\
& =\mathbf{1 , 3 9 8}
\end{aligned}
$$


Nilai Matriks evaluasi ekternal $=$ Total Peluang - Total Ancaman

$$
\begin{aligned}
& =2,318-1,021 \\
& =\mathbf{1 , 2 9 7}
\end{aligned}
$$

Posisi koordinat 1,398 pada sumbu $X$ dan 1,297 pada sumbu $Y$ ini dapat digambarkan dalam Matrix Space Analysis berikut:

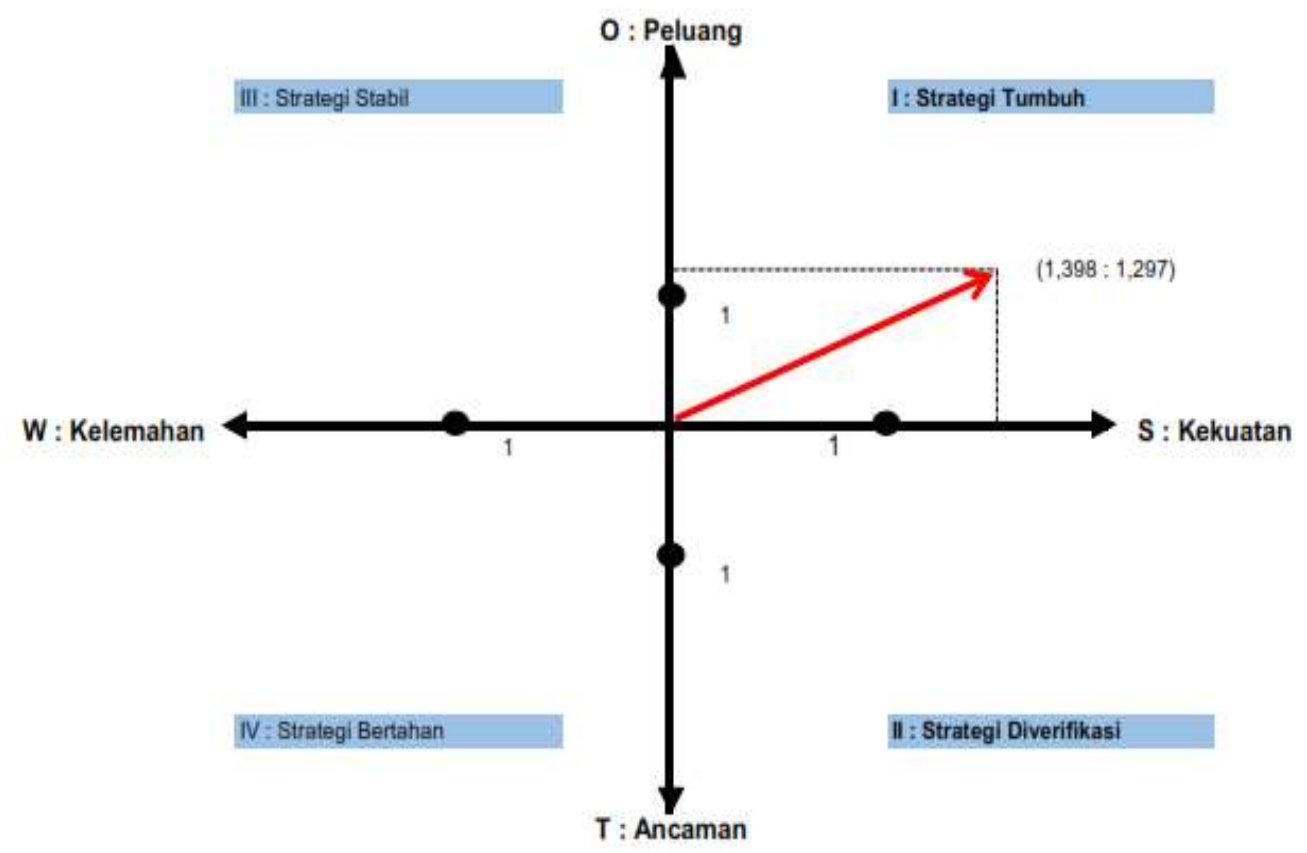

Gambar 1. Matrix Space Analysis

Dari Matriks di atas, posisi Strategi Pembelajaran PAK di PPA IO 0497 Benyamin Oebufu berada dalam wilayah Kuadran I (strategi bertumbuh). Posisi ini menggambarkan bahwa strategi bertumbuh untuk Strategi Pembelajaran PAK di PPA IO - 0497 Benyamin Oebufu sangat dimungkinkan karena kekuatan lebih besar dari kelemahan dan peluang lebih besar dari ancaman. 
Selanjutnya, item kekuatan, kelemahan, peluang dan ancaman dengan 5 bobot tertinggi dimasukkan dalam matriks SWOT untuk merumuskan strategi alternatif. Berdasakan hasil Matrix Space Analysis memungkinkan untuk memaksimalkan kekuatan (S) dan peluang $(\mathrm{O})$ dan meminimalkan kelemahan (W) dan ancaman (T). Hasilnya dapat dilihat pada matrix SWOT berikut :

Tabel 3. Matrix SWOT

\begin{tabular}{|c|c|c|}
\hline EFAS & $\begin{array}{l}\text { STRENGTH (S) } \\
\text { S1. Setiap Materi } \\
\text { Pembelajaran } \\
\text { berdasarkan ayat } \\
\text { Alkitab } \\
\text { S2. Bagian } \\
\text { pembelajaran yang } \\
\text { dikembangkan yaitu } \\
\text { kerohanian, } \\
\text { kognitif, fisik dan } \\
\text { sosial emosional } \\
\text { S3. Mengutamakan } \\
\text { penerapan Firman } \\
\text { Tuhan dari setiap } \\
\text { pembelajaran } \\
\text { dengan menghafal } \\
\text { Firman } \\
\text { S4. Hubungan } \\
\text { kekeluargaan yang } \\
\text { tinggi } \\
\text { S5. Pengajar sudah } \\
\text { mengenal latar } \\
\text { belakang anak }\end{array}$ & $\begin{array}{l}\text { WEAKNESS (W) } \\
\text { W1. Beban belajar } \\
\text { anak di Sekolah } \\
\text { dan PPA yang } \\
\text { semakin banyak } \\
\text { W2. Pembelajaran } \\
\text { masih bersifat } \\
\text { dasar, belum } \\
\text { mengembangkan } \\
\text { potensi anak } \\
\text { W3. Masalah anak } \\
\text { dalam keluarga } \\
\text { yang membuat } \\
\text { anak tidak ke PPA } \\
\text { W4. Tidak semua } \\
\text { pengajar berasal } \\
\text { dari lulusan guru } \\
\text { agama Kristen } \\
\text { W5. Belum } \\
\text { membelajarkan } \\
\text { materi yang sesuai } \\
\text { dengan } \\
\text { perkembangan } \\
\text { anak }\end{array}$ \\
\hline
\end{tabular}




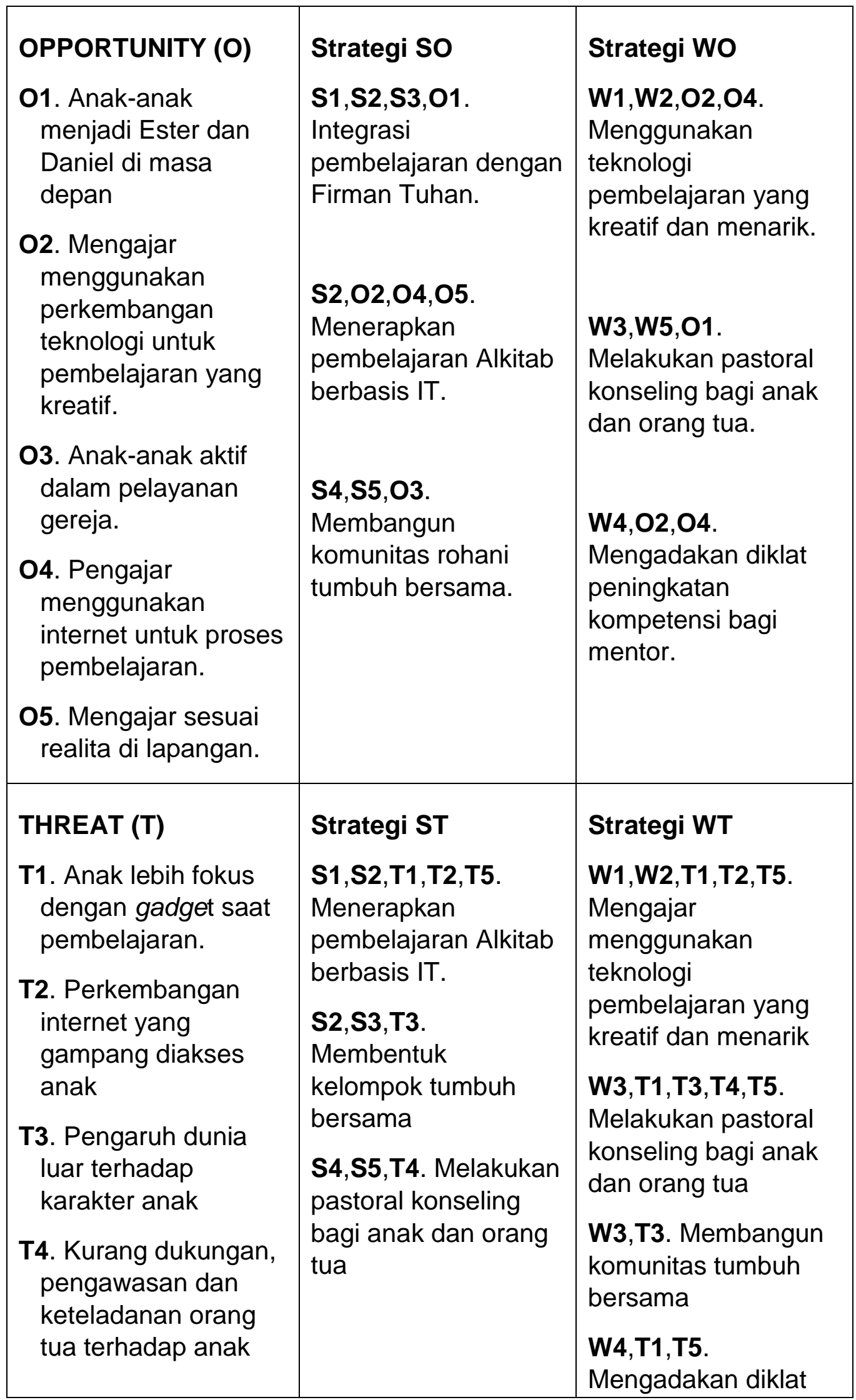




\begin{tabular}{|c|c|c|}
\hline $\begin{array}{l}\text { T5. Ketidakpedulian } \\
\text { anak terhadap } \\
\text { pembelajaran } \\
\text { Agama Kristen }\end{array}$ & & kompetensi mentor \\
\hline $\begin{array}{l}\text { THREAT (T) } \\
\text { T1. Anak lebih fokus } \\
\text { dengan gadget saat } \\
\text { pembelajaran. } \\
\text { T2. Perkembangan } \\
\text { internet yang } \\
\text { gampang diakses } \\
\text { anak } \\
\text { T3. Pengaruh dunia } \\
\text { luar terhadap } \\
\text { karakter anak } \\
\text { T4. Kurang dukungan, } \\
\text { pengawasan dan } \\
\text { keteladanan orang } \\
\text { tua terhadap anak } \\
\text { T5. Ketidakpedulian } \\
\text { anak terhadap } \\
\text { pembelajaran } \\
\text { Agama Kristen }\end{array}$ & $\begin{array}{l}\text { Strategi ST } \\
\text { S1,S2,T1,T2,T5. } \\
\text { Menerapkan } \\
\text { pembelajaran Alkitab } \\
\text { berbasis IT. } \\
\text { S2,S3,T3. } \\
\text { Membentuk } \\
\text { kelompok tumbuh } \\
\text { bersama } \\
\text { S4,S5,T4. Melakukan } \\
\text { pastoral konseling } \\
\text { bagi anak dan orang } \\
\text { tua }\end{array}$ & $\begin{array}{l}\text { Strategi WT } \\
\text { W1,W2,T1,T2,T5. } \\
\text { Mengajar } \\
\text { menggunakan } \\
\text { teknologi } \\
\text { pembelajaran yang } \\
\text { kreatif dan menarik } \\
\text { W3,T1,T3,T4,T5. } \\
\text { Melakukan pastoral } \\
\text { konseling bagi anak } \\
\text { dan orang tua } \\
\text { W3,T3. Membangun } \\
\text { komunitas tumbuh } \\
\text { bersama } \\
\text { W4,T1,T5. } \\
\text { Mengadakan diklat } \\
\text { kompetensi mentor }\end{array}$ \\
\hline
\end{tabular}

Berdasarkan tabel matriks SWOT di atas, alternatif strategi pembelajaran PAK di PPA IO-0497 Benyamin Oebufu adalah:

1. Integrasi pembelajaran dengan Firman Tuhan.

2. Menerapkan pembelajaran Alkitab berbasis teknologi yang kreatif dan menarik.

3. Membangun komunitas rohani tumbuh bersama.

4. Mengadakan diklat peningkatan kompetensi bagi mentor.

5. Melakukan pastoral konseling bagi anak dan orang tua. 


\section{PEMBAHASAN}

Hasil perhitungan skor di tabel IFAS dan EFAS menunjukkan bahwa skor kekuatan lebih besar dari kelemahan dan skor peluang lebih besar dari ancaman. Hal ini berarti bahwa PPA IO-0497 Benyamin Oebufu dapat memaksimalkan kekuatan untuk meminimalkan kelemahan serta memanfaatkan peluang dan menghindari ancaman. Berdasarkan hasil Matrix Space Analysis, posisi Strategi Pembelajaran PAK di PPA IO 0497 Benyamin Oebufu berada dalam wilayah Kuadran I (strategi bertumbuh). Pada kuadran ini, PPA IO - 0497 Benyamin Oebufu berada pada posisi yang baik untuk memaksimalkan kekuatan dan peluang. Kekuatan dan peluang dimaksimalkan dalam perumusan strategi untuk menekan kelemahan dan ancaman.

Pembelajaran PAK di PPA IO-0497 Benyamin Oebufu dapat dilakukan dengan beberapa strategi. Hal pertama yang dapat dilakukan adalah mengintegrasikan pembelajaran dengan Firman Tuhan. Hal ini bertujuan untuk menerapkan Firman Tuhan dalam setiap pembelajaran agar mengembangkan aspek kerohanian, kognitif, fisik dan sosial emosional. Dengan demikian anak-anak bisa menjadi Ester dan Daniel di masa depan.

Dalam Roma 10:17 menjelaskan bahwa iman itu timbul karena pendengaran akan firman Kristus. Selanjutnya Ibrani 11:3 menjelaskan bahwa karena iman kita mengerti bahwa alam semesta telah dijadikan oleh firman Allah. Hal ini berarti bahwa firman Tuhan harus 
diperdengarkan agar anak bertumbuh dalam iman. Tugas mengajar PAK memerlukan pengetahuan dalam mempresentasikan kehendak Allah serta memerlukan iman sebagai landasan pemahaman tentang Allah yang komprehensif. (Kolibu, 2017). Oleh karena itu, setiap pembelajaran di PPA IO-0497 Benyamin Oebufu perlu diintegrasikan dengan Alkitab. Hal ini bertujuan agar anak selalu mendengar Firman Tuhan sehingga imannya bertumbuh.

Hal kedua yang dapat dilakukan adalah menerapkan pembelajaran Alkitab berbasis teknologi yang kreatif dan menarik. Beban belajar anak di sekolah dan PPA yang semakin banyak serta internet yang gampang diakses anak menuntut pembelajaran Alkitab juga harus lebih kreatif dan menarik. Namun demikian perlu juga diperhatikan prosedur peggunaan sehingga anak tidak hanya fokus ke gadget ketika proses pembelajaran.

Untuk menghadirkan pendidikan Kristen yang kreatif di era milenial diperlukan pelatihan supaya pesan yang disampaikan berdampak luas dan positif. (Binsen S Sidjabat, 2019). Pesan pendidikan Kristen ini dapat disampaikan melalui media sosial, buku elektronik, vlog, blog maupun youtube. Kemudahan mengkases internet oleh anak PPA memudahkan mereka mengakses konten-konten yang berisi pengajaran PAK.

Hal ketiga, membangun komunitas rohani tumbuh bersama. Komunitas rohani tumbuh bersama atau kelompok tumbuh bersama merupakan wadah dimana jemaat memperoleh pengajaran Alkitab. (Subekti \& Pujiwati, 2019). Pendidikan karakter Kristen dapat dilakukan 
melalui jalur Alkitab dimana penelaahannya dikembangkan secara kreatif. (Binsen Samuel Sidjabat, 2019). Dalam kelompok ini anak PPA tidak saja belajar tentang isi Alkitab, tetapi juga belajar membangun diri, berbagi pengalaman hidup bersama Kristus dan tempat menemukan solusi dari persoalan yang dihadapi.

Tujuan dilaksanakannya kelompok tumbuh bersama adalah mendorong orang percaya bertumbuh ke arah kedewasaan penuh dalam Kristus, memperlengkapi orang percaya dengan pemahaman Alkitab dan melatih orang percaya dalam ketaatan terhadap Firman Tuhan. (Yuliati \& Yemima, 2019). Selain itu, kelompok tumbuh bersama mempermudah anak PPA IO-0497 Benyamin Oebufu belajar Firman Tuhan, belajar membangun diri serta mencegah pengaruh negatif dunia luar terhadap perkembangan karakter anak.

Hal keempat, mengadakan diklat peningkatan kompetensi bagi mentor. Latar belakang pendidikan mentor beragam, sementara mereka harus mengintegrasikan pembelajaran dengan Alkitab dan menggunakan teknologi pembelajaran yang kreatif dan menarik. Para mentor perlu mengikuti pendidikan dan pelatihan untuk mengembangkan kompetensi mereka. Pendidikan dan pelatihan yang diikuti yang berhubungan dengan tugas pokok dan fungsinya seperti desain pembelajaran, integrasi Alkitab, metode pembelajaran dan lain sebagainya.

Pentingnya pendidikan dan pelatihan dalam suatu organisasi adalah untuk memperbaiki kinerja pegawai yang meliputi pengetahuan 
dan keterampilan yang mendukung serta pembentukan pegawai sesuai yang diinginkan organisasi. (Pakpahan et al., 2014). Pada akhirnya program pendidikan dan pelatihan yang dilakukan suatu organisasi menunjang prestasi pegawai dan diharapkan dapat menjawab pencapaian/tujuan organisasi tersebut. (Fahmi et al., 2015). Ketika prestasi pegawai meningkat maka tujuan organisasi pun akan tercapai.

Hal terakhir, melakukan pastoral konseling bagi anak dan orang tua. Beban belajar yang banyak serta masalah dalam keluarga membuat anak malas untuk datang dan belajar di PPA. Konseling pastoral merupakan suatu upaya memberi pertolongan bagi orang yang mengalami kesulitan hidup dengan menghadiri situasi kehidupan nyata dalam terang Firman Tuhan. (Nainupu, 2009). Patoral konseling berfungsi menyembuhkan, menguatkan atau menopang, membimbing dan memperbaiki hubungan. (Wijayatsih, 2011).

Strategi pembelajaran PAK di PPA 1O-0497 Benyamin Oebufu ini didukung oleh kekuatan dari para pengajar yang walaupun bukan merupakan Iulusan Pendidikan Agama Kristen namun merupakan guru sekolah minggu yang sudah memiliki pengalaman di bidang pengajaran Pendidikan Agama Kristen. Untuk meningkatkan kompetensi para pengajar maka para pengajar diikutkan dalam berbagai diklat pengembangan kompetensi. Selain itu, teknologi yang yang terus berkembang memberikan peluang bagi para pengajar untuk melakukan inovasi dalam pembelajaran Agama Kristen. 
Adanya hubungan yang baik antara pengajar, orang tua dan anak memungkinkan dibentuk kelompok tumbuh bersama sehingga anak bisa saling berbagi dan membangun dalam pembelajaran Agama Kristen. Pastoral konseling pun dapat dilaksanakan kepada orang tua dan anak yang memiliki masalah di rumah.

\section{KESIMPULAN}

Berdasarkan pemaparan dan pembahasan di atas maka disimpulkan bahwa PPA IO-0497 Benyamin Oebufu memiliki kekuatan yaitu setiap materi pembelajaran berdasarkan ayat Alkitab, bagian pembelajaran yang dikembangkan yaitu kerohanian, kognitif, fisik dan sosial emosional, mengutamakan penerapan Firman Tuhan dari setiap pembelajaran dengan menghafal Firman, hubungan kekeluargaan yang tinggi serta pengajar sudah mengenal latar belakang anak. Kelemahannya yaitu beban belajar anak di Sekolah dan PPA yang semakin banyak, pembelajaran masih bersifat dasar, masalah anak dalam keluarga yang membuat anak tidak ke PPA, tidak semua pengajar berasal dari lulusan guru agama Kristen serta belum membelajarkan materi yang sesuai dengan perkembangan anak.

Peluang yang dimiliki PPA IO-0497 Benyamin Oebufu adalah anakanak menjadi Ester dan Daniel di masa depan, mengajar menggunakan perkembangan teknologi untuk pembelajaran yang kreatif, anak-anak aktif dalam pelayanan gereja, pengajar menggunakan internet untuk proses pembelajaran serta mengajar sesuai realita di lapangan. Ancamannya 
adalah anak lebih fokus dengan gadget saat pembelajaran, perkembangan internet yang gampang diakses anak, pengaruh dunia luar terhadap karakter anak, kurang dukungan, pengawasan dan keteladanan orang tua terhadap anak serta ketidakpedulian anak terhadap pembelajaran Agama Kristen.

Hasil matrix space analysis menunjukkan posisi strategi pembelajaran PAK di PPA IO - 0497 Benyamin Oebufu berada dalam wilayah Kuadran I, artinya strategi bertumbuh sangat dimungkinkan karena kekuatan lebih besar dari kelemahan dan peluang lebih besar dari ancaman. Strategi pembelajaran PAK di PPA IO-0497 Benyamin Oebufu adalah integrasi pembelajaran dengan Firman Tuhan, menerapkan pembelajaran Alkitab berbasis teknologi yang kreatif dan menarik, membangun komunitas rohani tumbuh bersama, mengadakan diklat peningkatan kompetensi bagi mentor serta melakukan pastoral konseling bagi anak dan orang tua.

\section{DAFTAR PUSTAKA}

Alawiyah, F. (2017). Standar Nasional Pendidikan Dasar dan Menengah. Jurnal Aspirasi, 8(1), 81-92.

Anwar, M. C., \& Utami, M. C. (2012). Analisis SWOT pada Strategi Bisnis dalam Kompetisi Pasar. Jurnal Sistem Informasi, 5(1), 1-9.

Arifianto, E. Y. (2017). Strategi Pengembangan Sumber Daya Manusia dengan Pendekatan Pola Komunikasi Efektif dalam Mewujudkan Konsep Malang Smart City. Jurnal Komunikasi Global, 6(2), 175-184.

Baharuddin. (2019). Manajemen strategik mutu pendidikan. Jurnal Idaarah, III(36), 155-163.

Chamidi, A. S., Lestari, A., Ariskawanti, E., Hidayati, K. D., Baety, N. N. H., 
Rohmah, N., Rosydah, \& Istikomah, T. (2019). Analisa SWOT Manajemen Pendidikan di SMK Maarif 1 Kebumen. Ejournal, Cakrawala: Studi Manajemen Pendidikan Islam Dan Studi Sosial, 3(2), 2580-9385.

Fahmi, F. H., Pratiwi, R. N., \& Trisnawati. (2015). Pengaruh Pendidikan dan Pelatihan (DIKLAT) Terhadap Prestasi Kerja (Studi pada Dinas Kesehatan Kabupaten Pamekasan). Jurnal Administrasi Publik, 3(11), 1809-1813.

Gulo, S. (2017). Prinsip Pendidikan Agama Kristen Dalam Keluarga Bagi Keluarga Banua Niha Keriso Protestan (BNKP) Gunung Sitoli. JURNAL GLOBAL EDUKASI, 3(3), 452-456.

Hasugian, J. W. (2019). Kurikulum dan Pembelajaran Warga Jemaat Dewasa di Gereja. KURIOS: Jurnal Teologi dan Pendidikan Agama Kristen, 5(1), 36-53.

Kamayuda, D. M. D., \& Krismanda, M. A. (2016). Perencanaan Strategi Bersaing Sekolah Dalam Meningkatkan Mutu Pendidikan Di Sekolah Swasta Salatiga. Satya Widya, 32(2), 79-91. https://doi.org/10.24246/j.sw.2016.v32.i2.p79-91

Khori, A. (2016). Manajemen Strategik dan Mutu Pendidikan Islam. Manageria : Jurnal Manajemen Pendidikan Islam, I(1), 75-99.

Kolibu, D. R. (2017). Tantangan Pelayanan Dalam Tugas Mengajar PAK: Kajian Teologis, Pedagogis Implmentasi Pendidikan Agama Kristen Sebagai Integrasi Iman dan IImu. Shanan Jurnal Pendidikan Agama Kristen, 1(2), 132-150.

Nainupu, M. (2009). Konseling Pastoral dalam Gereja: RES SINE QUA NON. JTA, 20(11), 78-100.

Oci, M. (2018). Pengaruh Pengelolaan Kelas Dalam Pelajaran Agama Kristen Terhadap Prestasi Belajar Siswa Di SMP Kanaan Ungaran Tahun Ajaran 2017-2018. Jurnal Fidei, 1(2), 199-218.

Pakpahan, E. S., Siswidiyanto, \& Sukanto. (2014). Pengaruh Pendidikan Dan Pelatihan Terhadap Kinerja Pegawai (Studi Pada Badan Kepegawaian Daerah Kota Malang). Jurnal Administrasi Publik, 2(1), 116-121.

Primadona, Y., \& Rafiqi, Y. (2019). Analisis swot pada strategi persaingan usaha minimarket madina purbaratu kota tasikmalaya. Jurnal Ekonomi Syariah, 4(1), 49-60.

Rindaningsih, I. (2012). Pengembangan Model Manajemen Sategik 
Berbasis (Beyond Center and Circle Time) BCCT Pada PAUD. Jurnal Pedagogia, 1(2), 213-223.

Shamadiyah, N. (2017). Analisis Swot Strategi Pemberdayaan Masyarakat Program Penataan Lingkungan Permukiman Komunitas Di Kelurahan Suryatmajan, Kota Yogyakarta. Agrifo: Jurnal Agribisnis Universitas Malikussaleh, 2(1), 58-66. https://doi.org/10.29103/ag.v2i1.506

Sidjabat, Binsen S. (2019). MERETAS POLARISASI PENDIDIKAN KRISTIANI: Sebuah Pengantar tentang Arah Pendidikan Kristiani di Gereja, Akademia, dan Ruang Publik. Indonesian Journal of Theology, 7(1), 7-24.

Sidjabat, Binsen Samuel. (2019). Kerangka Kurikulum Pendidikan Agama Kristen Berbasis Karakter di Perguruan Tinggi. Jurnal Jaffray, 17(1), 73-90. https://doi.org/10.25278/jj71.v17i1.314

Subekti, T., \& Pujiwati. (2019). Pemuridan Misioner dalam Menyiapkan Perluasan Gereja Lokal. EPIGRAPHE: Jurnal Teologi dan Pelayanan Kristiani, 3(2), 157-172. https://doi.org/10.33991/epigraphe.v3i2.126

Sujoko, E. (2017). Strategi Peningkatan Mutu Sekolah Berdasarkan Analisis Swot Di Sekolah Menengah Pertama. Kelola: Manajemen Pendidikan, 4(1), 1-14.

Wijayatsih, H. (2011). Pendampingan dan Konseling Pastoral. Gema Teologi, 35(1/2), 3-10.

Yulianingsih, D., \& Gaol, S. M. M. L. (2019). Keterampilan Guru PAK Untuk Meningkatkan Minat Belajar Murid Dalam Proses Pembelajaran Di Kelas. Jurnal Fidei, 2(1), 100-119.

Yuliati, \& Yemima, K. (2019). MODEL PEMURIDAN KONSELING BAGI ALUMNUS PERGURUAN TINGGI LULUSAN BARU (FRESH GRADUATE) YANG MENGINGKARI PANGGILAN PELAYANAN. Gamaliel :Teologi Praktika, 1(1), 26-40. 